\title{
Are all Economics Graduate Cohorts Created Equal? Gender, Job Openings, and Research Productivity ${ }^{1}$
}

\author{
John P. Conley \\ Vanderbilt University \\ Ali Sina Önder \\ University of Bayreuth \\ Benno Torgler \\ Queensland University of Technology and CREMA
}

\begin{abstract}
Using life cycle publication data of 9,368 economics $\mathrm{PhD}$ graduates from 127 U.S. institutions between 1987 and 1996, we compare research productivities of male and female graduates, and how these correlate with macroeconomic conditions prior to starting graduate studies and with availability of academic jobs at the time of graduation. We find that availability of academic jobs is positively correlated with research productivity for both male and female graduates. Unfavorable employment conditions prior to starting graduate education are negatively correlated with female graduates' research productivity and positively related to male graduates' productivity.
\end{abstract}

Keywords: Research Productivity, Human Capital, Graduate Education, Gender Differences JEL Codes: A23, I23, J16, J24

${ }^{1}$ We would like to thank John Siegfried and the AEA staff for making JEL publication data available to us, as well as Jonathan Lee, Peter Kozciuk, and Ho Fai Chan for excellent research assistance. We thank Mario J. Crucini and Robert A. Driskill for valuable comments and earlier collaborations using this dataset. We thank David Stadelmann for helpful comments. We take responsibility for any errors that remain.

Conley: Vanderbilt University, Dept. of Economics, Calhoun Hall 415, 37240 Nashville, TN, USA (Email: j.p.conley@vanderbilt.edu )

Önder: (corresponding author) University of Bayreuth, Dept. of Economics, RW-1, VWL-E, Universitätsstr. 30, 95447 Bayreuth, Germany (Email: ali-sina.oender@uni-bayreuth.de Phone: +49 921 556085, Fax: +49 921 556082)

Torgler: Queensland University of Technology, School of Economics and Finance, 2 George St, 4000 Brisbane QLD, Australia (Email: benno.torgler@qut.edu.au) 


\section{Introduction and Motivation}

Conley et al. (2013) provide strong empirical evidence that research publication quality of economics $\mathrm{PhDs}$ has had an overall negative time-trend over the last two decades, and they link this overall negative trend to the increase in journal publication lags and in research complexity in economics over decades, both of which have been documented by Ellison (2002). Research quality of economics PhDs show in addition to the overall negative time-trend also smaller variations across cohorts within a couple of years. In this paper we investigate if and how these cohorts' research productivities correlate with time-specific conditions of the overall and the academic job market, and in particular we focus on research productivity differences between male and female PhDs.

Each cohort faces time-specific economic conditions at two crucial points: availability of lucrative job opportunities is an important decision factor at the time when college students contemplate whether to invest in graduate education or not, and for those who decide to do so the availability of academic jobs at the time of finishing graduate school is crucial. During times of high unemployment students coming out of college find career opportunities that are either slim or not lucrative enough (Oreopoulos et al. 2012), and hence they may prefer to enroll in graduate education. This will enlarge the applicant pool of graduate schools, and assuming that admission committees do not make systematic mistakes in recognizing and recruiting talented applicants, one would expect to observe more talented incoming classes being assembled (Boehm and Watzinger 2015). Academic job opportunities at the end of graduate education are also crucial, because first job placements of economics PhDs have a significant and causal impact on their life-long research productivity (Oyer 2006).

Bedard and Herman (2008) investigate cyclical patterns of advanced degree enrollment across genders and document that males' enrollment in graduate education in most fields is countercyclical whereas female enrollment is acyclical. There exists an extensive literature documenting and investigating productivity differences between male and female researchers in academia ${ }^{2}$, and it is important to understand how cyclical factors may drive such differences. Although our results yield only suggestive correlations rather than causal interrelations, we provide a basic empirical analysis and discuss how the observed productivity differences might be explained in light of the observed cyclical patterns.

\footnotetext{
2 See, e.g., Ginther and Kahn (2004), Barbezat (2006), Hilmer and Hilmer (2007), Hale and Regev (2014) for gender gap analysis in economics; Ceci et al. (2014) for math-intensive fields.
} 
We use a unique dataset on publication records of economics $\mathrm{PhDs}$ graduating from U.S. institutions ${ }^{3}$ between 1987 and 1996. Research productivity of these individuals is almost perfectly measurable (at least retrospectively) as it reveals itself in number and quality of publications. We investigate if and how unemployment rates prevailing in the economy prior to starting graduate education and availability of academic jobs at graduation are correlated with observed academic productivities of economics PhDs. We find no significant correlation between research productivity and business cycle at the start of graduate studies for the pooled sample. Availability of academic job openings at the end of $\mathrm{PhD}$, on the other hand, has a positive effect on research productivity (measured in number of publications), and this finding is in line with Oyer (2006) who suggested that a first job where research skills can be built further has positive effect on research output of graduates.

When gender is introduced into our investigation, an interesting result is revealed: the correlation between research productivity and business cycle at the start of graduate studies that is insignificant for the pooled sample, turns out significant when sample is split between male and female $\mathrm{PhDs}$, and we find that unemployment rates prior to starting graduate school are correlated in opposite ways with female and male graduates' research productivity. This correlation is positive and significant for male $\mathrm{PhDs}$, negative and significant for female $\mathrm{PhDs}$, suggesting that the above mentioned mechanism for selection into graduate education operates differently for men and women.

This paper contributes to the current literature by documenting research output of male and female economics $\mathrm{PhDs}$ and further linking differences in research productivity between male and female $\mathrm{PhDs}$ to possible differences in how men and women weigh human capital investment and career risk. A low opportunity cost of human capital investment in times of high unemployment can be outweighed by increased risk and uncertainty concerning availability of future placement and tenure opportunities. Men and women seem to differ in how they weigh these two costs.

\footnotetext{
${ }^{3} \mathrm{PhD}$ holders from U.S. institutions that obtained their undergraduate degree outside the U.S. make about $40 \%$ to $50 \%$ of graduates as documented by Oyer (2006) and Grove and $\mathrm{Wu}$ (2007). $\mathrm{PhD}$ applicants from abroad are affected by unemployment rates prior to $\mathrm{PhD}$ in similar ways as native applicants. They have to compete for the limited incoming class seats and assistantships. Assuming that quality of foreign applicant pool remains constant, a significant increase in quality of native applicant pool will affect quality composition of the incoming class. Moreover, availability of assistantships and scholarships are mostly procyclical which makes the competition even fiercer during times of unfavorable economic conditions.
} 


\section{Data Description}

Table 1 documents number of economics PhDs graduating from U.S. institutions between 1987 and 1996. These data are provided by the American Economic Association. Of 9,368 freshly minted $\mathrm{PhDs}$ in that period, 7,339 are male, and 2,029 are female. We obtain complete publication records of economics PhDs by merging the list of economics $\mathrm{PhDs}$ with the list of publications provided by the EconLit from 1986 to 2005, and we restrict our analysis to peer-reviewed journal publications only. That way, we are able to create a complete list of publications for each graduate from one year before graduation up to nine years after graduation. We focus in most of our analysis on those graduates who publish at least once within six years after graduation, and we refer to this group as "publishing PhDs" throughout this paper. Of 9,368 PhDs we have in our pooled sample, 4,611 turn out to be "publishing PhDs". Table 1 shows in detail number of economics PhDs by graduation year and gender. Furthermore table 1 also documents how many of them qualify to be a publishing $\mathrm{PhD}$ based on the above definition. The empirical finding that about half of economics $\mathrm{PhDs}$ never ever publish has already received great attention and has been discussed in detail by Conley and Önder (2014). It is important to note that the above definition of a "publishing PhD" does not guarantee that this person has had an initial placement that requires publication of research.

Table 1. Number of Economics PhDs Graduating from U.S. Institutions

\begin{tabular}{|c|c|c|c|c|c|c|c|c|}
\hline & All Graduates & Male & Female & $\begin{array}{c}\text { Percentage of } \\
\text { Females in } \\
\text { all Graduates } \\
\end{array}$ & $\begin{array}{c}\text { Publishing } \\
\text { Male }\end{array}$ & $\begin{array}{l}\text { Publishing } \\
\text { Female } \\
\end{array}$ & $\begin{array}{c}\text { Percentage of } \\
\text { Publishing Male } \\
\text { in all Male } \\
\text { Graduates } \\
\end{array}$ & $\begin{array}{c}\text { Percentage of } \\
\text { Publishing } \\
\text { Female in all } \\
\text { Female } \\
\text { Graduates } \\
\end{array}$ \\
\hline 1987 & 684 & 547 & 137 & 20.0 & 265 & 55 & 48.4 & 40.1 \\
\hline 1988 & 840 & 670 & 170 & 20.2 & 312 & 72 & 46.6 & 42.4 \\
\hline 1989 & 984 & 794 & 190 & 19.3 & 382 & 100 & 48.1 & 52.6 \\
\hline 1990 & 943 & 759 & 184 & 19.5 & 377 & 82 & 49.7 & 44.6 \\
\hline 1991 & 918 & 729 & 189 & 20.6 & 375 & 85 & 51.4 & 45.0 \\
\hline 1992 & 928 & 722 & 206 & 22.2 & 357 & 106 & 49.4 & 51.5 \\
\hline 1993 & 1067 & 814 & 253 & 23.7 & 413 & 124 & 50.7 & 49.0 \\
\hline 1994 & 1032 & 783 & 249 & 24.1 & 405 & 120 & 51.7 & 48.2 \\
\hline 1995 & 1025 & 782 & 243 & 23.7 & 404 & 94 & 51.7 & 38.7 \\
\hline 1996 & 947 & 739 & 208 & 22.0 & 383 & 100 & 51.8 & 48.1 \\
\hline Total & 9368 & 7339 & 2029 & 21.7 & 3673 & 938 & 50.0 & 46.2 \\
\hline
\end{tabular}

About half of all male graduates in our sample published at least once within six years after graduation. This ratio varies little across cohorts of male graduates from 1987 to 1996, fluctuating 
between $46.6 \%$ and $51.8 \%$. Publishing female graduates make up about $46 \%$ of all female graduates in our sample. This ratio has a higher variation across cohorts compared to that for male graduates, fluctuating between $38.7 \%$ and $52.6 \%$.

We have 4,611 publishing PhDs in our sample that have accumulated a total of 27,694 articles in 831 different journals cited in the EconLit. We measure research productivity by total count of publications (raw counts of publications) as well as by quality adjusted number of publications at the end of six and nine years after graduation. In order to account for publication quality we weigh each publication by the quality index provided by Kalaitzidakis et al. (2003), where the American Economic Review (AER) is assigned the highest quality. We use their journal quality indexes as an exchange rate between the AER and other journals ${ }^{4}$; measuring the quality of an individual article in a given journal by expressing it as a fraction of an AER article. We refer to this quality measure as the number of AER equivalent publications. We discount for coauthorship in a publication by dividing its quality index by the number of coauthors and assigning each coauthor an equal share.

The aim of our subsequent analysis is the investigation of how the overall macroeconomic environment in the U.S. prior to starting graduate studies, and how the availability of faculty or research positions upon completion of graduate studies might affect publication quantity and quality of publishing graduates. According to Stock et al. (2009), it takes five to six years to graduate from an economics $\mathrm{PhD}$ program in the U.S., on average. Since most graduate programs have application deadlines in January for admission in the next fall term, and applicants should have their standardized test scores ready by then, it is safe to assume that a potential graduate student should decide whether to apply for graduate school about a year before starting. The overall unemployment rate prevailing in the U.S. economy in a year is the measure we employ for assessing the overall macroeconomic environment in the U.S. in that year. Using the Federal Reserve Economic Database we obtain annual unemployment rate at seven years before the graduation year for each cohort, hence for years 1980-1989.

A regular academic job market takes place during the first half of spring semester, and academic jobs are advertised in the "Job Openings for Economists" (JOE) listings of the American Economic Association during the fall semester before that. Assuming that one graduates after the job search process is concluded, most relevant data on JOE originate from the year before finishing $\mathrm{PhD}$. We obtain the number of academic job openings (we denote these data as JOE in the subsequent figures

\footnotetext{
${ }^{4}$ All journals below top 65 are assigned a constant quality index of 0.012 . See Conley et al. (2013) for more details about this procedure.
} 
and tables) from the American Economic Association in the year prior to graduation for each cohort, hence for years 1986-1995.

For our sample consisting of economics PhDs graduating between 1987 and 1996, we have corresponding U.S. unemployment rates prior to their start of graduate studies, namely for years 1980 to 1989 , and we have junior academic job market openings for years 1986 to 1995 . These periods are especially interesting because they cover times of unusually high unemployment rates and recovery thereafter. Figure 1 shows trends in unemployment rates prior to start and number of academic job openings at the end of graduate studies faced by each cohort. Data in figure 1 read as follows: PhDs who obtained their degree in 1987 faced an unemployment rate of 7.18 at time of application for graduate education. When this cohort was participating in the academic job market, number of academic job ads in the JOE was $1134^{5}$. Figure 1 reveals a strong correlation (0.76) between number of available positions at the end of graduate studies and unemployment rates prior to starting graduate studies. This observation is not surprising, because a brief look at business cycle statistics provided by the National Bureau of Economic Research reveals that the U.S. economy has completed its business cycles in about five to seven years on average since 1919, hence the high correlation of unemployment rates and position openings that are six years apart of one another in our data.

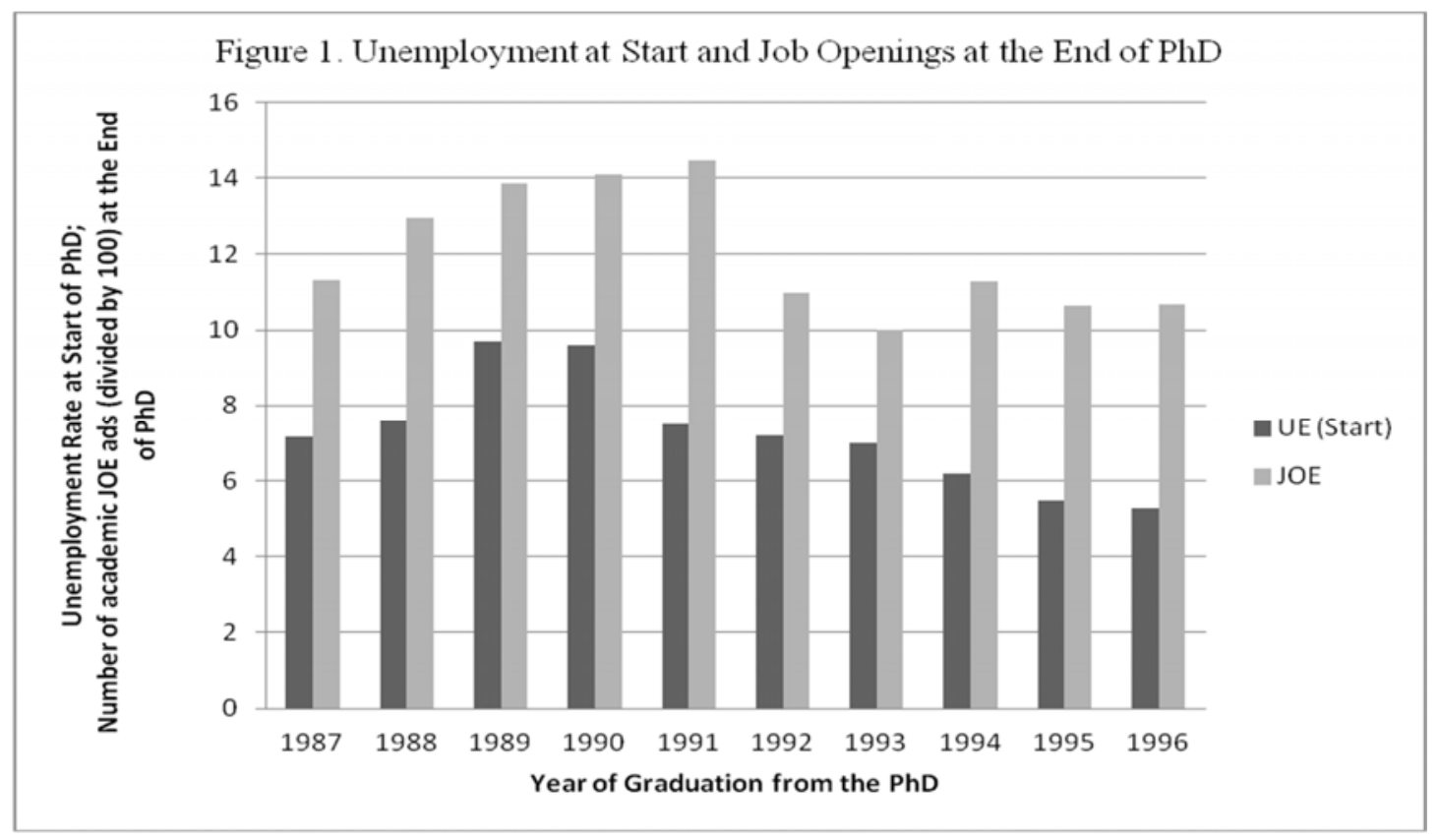

\footnotetext{
${ }^{5} 1134$ is the actual value, however values related to JOE in Figure 1 are scaled by 100 so that the JOE-
} column for the 1987 cohort reads 11.3. 
Figure 2 shows the average number of total publications (not adjusted for quality and coauthorship) achieved by male and female PhDs in respective cohorts by the end of six years after graduation. Description of dependent and independent variables used in the subsequent analysis are shown in table 2.

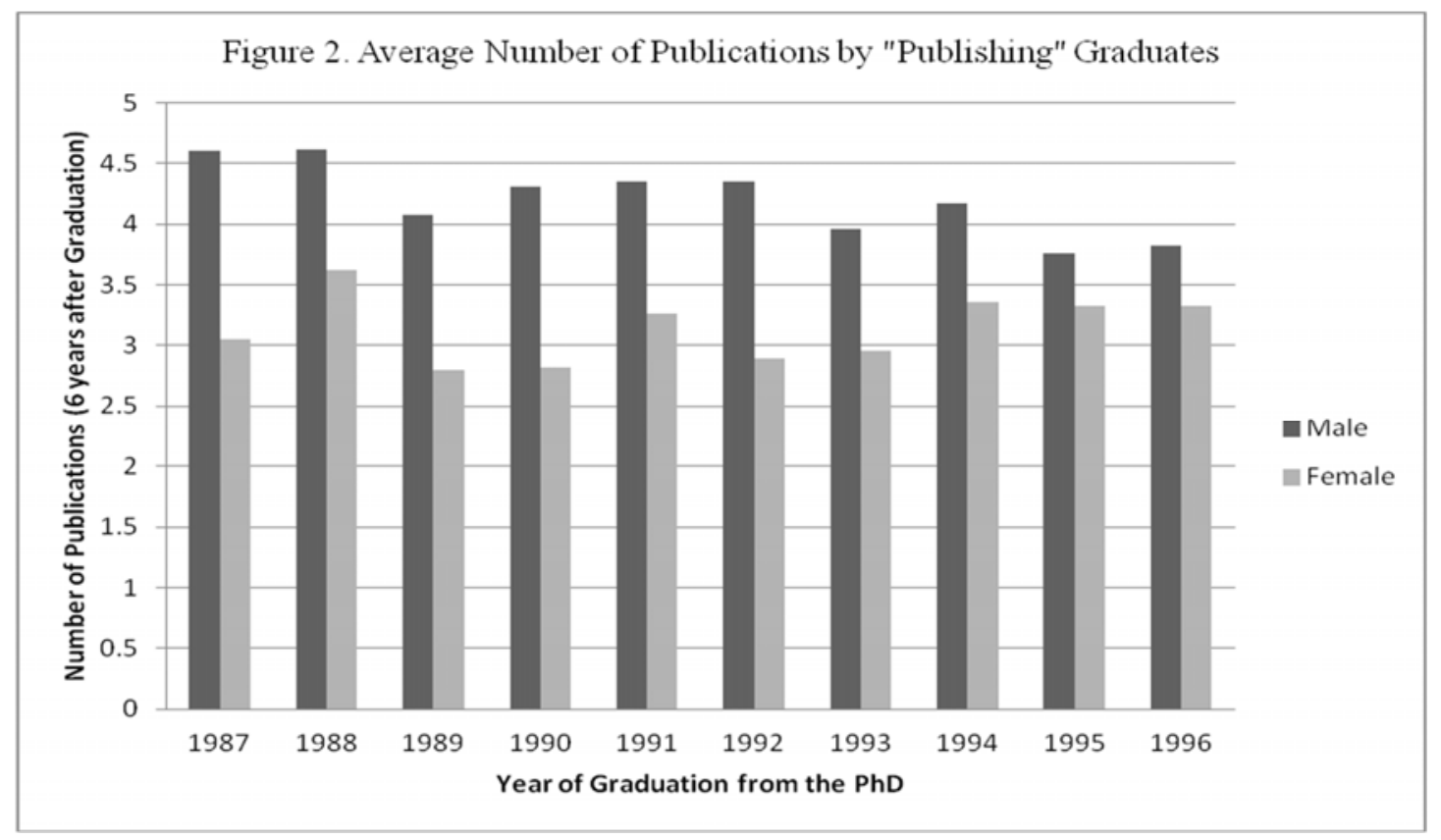


Table 2. Descriptive Statistics

A. Independent Variables

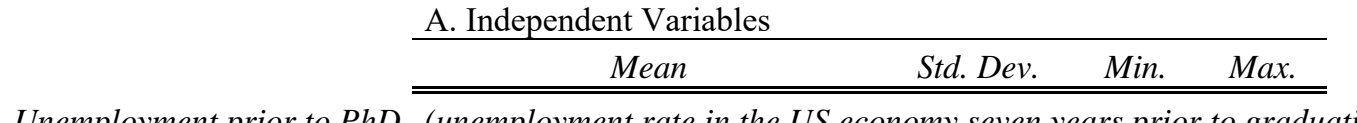

Unemployment prior to $\mathrm{PhD}$ (unemployment rate in the US economy seven years prior to graduation year)

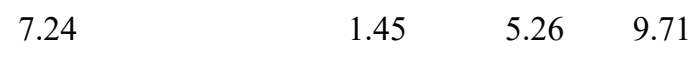

JOE (number of academic job openings (rescaled dividing by 100) published in "JOE" the year before graduation year)

$\begin{array}{rcccc} & 11.99 & 1.59 & 10.02 & 14.47 \\ \text { Change in Unemployment (prior to PhD) } & -0.115 & 1.09 & -2.09 & 2.09 \\ \text { Change in JOE } & -0.112 & 1.369 & -3.49 & 1.6\end{array}$

Top 30 (equals one, if graduated from a top 30 institution)*
0.622
0.48
0

Female (equals one, if female)

$$
0.203
$$

\begin{tabular}{|c|c|c|c|c|c|c|c|}
\hline \multicolumn{4}{|c|}{6 years after $P h D$} & \multicolumn{4}{|c|}{9 years after $P h D$} \\
\hline Mean & Std. Dev. & Min. & Max. & Mean & Std. Dev. & Min. & Max. \\
\hline
\end{tabular}

*) Top 30 economics departments in the U.S. are based on rankings presented in Coupe (2003).

Total Number of Publications (total number of publications, including no control for quality, not discounting for coauthorship)

\begin{tabular}{rlccc|cccc} 
for all graduates & 3.96 & 3.7 & 1 & 32 & 5.88 & 5.66 & 1 & 56 \\
for male graduates & 4.18 & 3.93 & 1 & 32 & 6.23 & 6 & 1 & 56 \\
for female graduates & 3.13 & 2.46 & 1 & 16 & 4.5 & 3.79 & 1 & 26
\end{tabular}

Total Number of AER Eq. Publications (AER-equivalent number of publications accumulated, discounting for coauthorship)**

\begin{tabular}{rllll|llll} 
for all graduates & 0.32 & 0.63 & 0.004 & 8.85 & 0.45 & 0.89 & 0.004 & 10.26 \\
for male graduates & 0.34 & 0.67 & 0.004 & 8.85 & 0.48 & 0.94 & 0.004 & 10.26 \\
for female graduates & 0.24 & 0.46 & 0.004 & 3.73 & 0.33 & 0.63 & 0.004 & 5.21
\end{tabular}

At least 1 Publication in 6 years after PhD (equals one, if published at least once within 6 years after graduation)

\begin{tabular}{rcccc|} 
for all graduates & 0.49 & 0.5 & 0 & 1 \\
for male graduates & 0.5 & 0.5 & 0 & 1 \\
for female graduates & 0.46 & 0.5 & 0 & 1 \\
\cline { 2 - 5 }
\end{tabular}

**) See text for details on how to calculate AER-equivalence of a publication. 
Research productivity of publishing graduates has an extremely skewed distribution, as documented by Conley et al. (2013) and Conley and Önder (2014). Therefore publication data have more than one dimension to consider, and these figures should be seen as merely descriptive statistics. We employ appropriate regression analyses to unveil various patterns in the next section.

\section{Results and Discussion}

Marginal effects from the negative binomial regression of total number of publications accumulated at six and nine years after graduation on unemployment rate prior to starting graduate studies (labeled UE (Start)) and its change from previous year, on academic job availability at the end of graduate studies (labeled JOE) and its change from previous year, and on other characteristics of $\mathrm{PhDs}$ are shown in table $3^{6}$. The two characteristics of $\mathrm{PhDs}$ we pay attention to are whether they did graduate from a top thirty economics department and whether they are male or female. The dummy variable "top 30 " equals one if the individual is a graduate of a top thirty economics department and zero otherwise. The dummy variable "female" equals one if the individual is female and zero otherwise.

In panel A of table 3 we use the total raw number of publications (not adjusted for quality and not discounted for coauthorship) accumulated at six years after graduation as the dependent variable, and we present results using the pooled sample (columns 1 to 5), sample restricted to males only (columns 6 to 10), and sample restricted to females only (columns 11 to 15). Neither unemployment rate prior to starting graduate school nor its change turn out to be statistically significant for the pooled sample in specifications from (1) to (5). The number of academic job openings is significant in one specification, but it becomes insignificant when we control for annual changes in the number of academic job openings or for unemployment prior to starting $\mathrm{PhD}$.

\footnotetext{
${ }^{6}$ Robust standard errors are calculated for the negative binomial distribution in table 3 . We use clustered standard errors at graduation year and top thirty departments in subsequent analysis.
} 
Table 3. Unemployment and Research Productivity (Total Number of Publications)

\begin{tabular}{|c|c|c|c|c|c|c|c|c|c|c|c|c|c|c|c|}
\hline & \multicolumn{15}{|c|}{ A. 6 Years After Obtaining $\mathrm{PhD}$} \\
\hline & \multicolumn{5}{|c|}{ All } & \multicolumn{5}{|c|}{ Male } & \multicolumn{5}{|c|}{ Female } \\
\hline & (1) & (2) & (3) & (4) & (5) & (6) & (7) & (8) & (9) & (10) & (11) & (12) & (13) & (14) & (15) \\
\hline \multirow[t]{2}{*}{ UE (Start) } & 0.047 & & 0.056 & & -0.018 & $0.093^{* *}$ & & $0.101^{* *}$ & & 0.041 & $-0.110^{* *}$ & & -0.098 & & $-0.211^{* *}$ \\
\hline & [0.035] & & [0.040] & & [0.055] & [0.043] & & {$[0.048]$} & & {$[0.067]$} & {$[0.056]$} & & {$[0.063]$} & & [0.084] \\
\hline \multirow[t]{2}{*}{ JOE } & & $0.065^{* *}$ & & 0.059 & 0.077 & & $0.090^{* *}$ & & $0.099 * *$ & 0.062 & & -0.022 & & -0.072 & $0.122^{*}$ \\
\hline & & [0.032] & & [0.037] & [0.050] & & {$[0.039]$} & & [0.045] & {$[0.062]$} & & [0.049] & & {$[0.056]$} & [0.074] \\
\hline \multirow[t]{2}{*}{$\triangle$ in UE (Start) } & & & -0.024 & & & & & -0.021 & & & & & -0.032 & & \\
\hline & & & [0.055] & & & & & {$[0.066]$} & & & & & [0.082] & & \\
\hline \multirow[t]{2}{*}{$\triangle$ in JOE } & & & & 0.014 & & & & & -0.022 & & & & & $0.122 *$ & \\
\hline & & & & [0.045] & & & & & {$[0.055]$} & & & & & {$[0.067]$} & \\
\hline \multirow[t]{2}{*}{ Тор 30} & $0.821 * * *$ & $0.823 * * *$ & $0.820^{* * *}$ & $0.823 * * *$ & $0.822 * * *$ & $0.870 * * *$ & $0.873^{* * *}$ & $0.869^{* * *}$ & $0.872 * * *$ & $0.873^{* * *}$ & $0.644 * * *$ & $0.654 * * *$ & $0.644 * * *$ & $0.654 * * *$ & $0.639 * * *$ \\
\hline & [0.108] & [0.108] & [0.108] & [0.108] & [0.108] & [0.132] & [0.132] & {$[0.132]$} & {$[0.132]$} & [0.132] & {$[0.158]$} & {$[0.158]$} & {$[0.158]$} & {$[0.158]$} & [0.158] \\
\hline \multirow[t]{2}{*}{ Female } & $-1.025^{* * *}$ & $-1.021 * * *$ & $-1.025 * * *$ & $-1.021 * * *$ & $-1.021 * * *$ & & & & & & & & & & \\
\hline & [0.102] & [0.102] & [0.102] & [0.102] & [0.102] & & & & & & & & & & \\
\hline Observ. & 4611 & 4611 & 4611 & 4611 & 4611 & 3673 & 3673 & 3673 & 3673 & 3673 & 938 & 938 & 938 & 938 & 938 \\
\hline Wald Stat. & 155.7 & 159 & 155.8 & 159.5 & 159.7 & 44.11 & 45.89 & 44.18 & 45.86 & 45.98 & 20.84 & 16.44 & 20.79 & 22.15 & 24.82 \\
\hline Log Likelihood & -11012 & -11011 & -11012 & -11011 & -11011 & -9005 & -9005 & -9005 & -9005 & -9004 & -1980 & -1982 & -1980 & -1980 & -1979 \\
\hline
\end{tabular}


Table 3. Unemployment and Research Productivity (Total Number of Publications) (cont.'ed)

\begin{tabular}{|c|c|c|c|c|c|c|c|c|c|c|c|c|c|c|c|}
\hline & \multicolumn{15}{|c|}{ B. 9 Years After Obtaining $\mathrm{PhD}$} \\
\hline & \multicolumn{5}{|c|}{ All } & \multicolumn{5}{|c|}{ Male } & \multicolumn{5}{|c|}{ Female } \\
\hline & (1) & (2) & (3) & (4) & (5) & (6) & (7) & (8) & (9) & (10) & (11) & (12) & (13) & (14) & (15) \\
\hline \multirow[t]{2}{*}{ UE (Start) } & 0.072 & & 0.067 & & -0.009 & $0.143^{* *}$ & & $0.136^{*}$ & & 0.074 & $-0.152^{*}$ & & -0.154 & & $-0.264^{* *}$ \\
\hline & [0.055] & & {$[0.062]$} & & [0.084] & {$[0.066]$} & & {$[0.074]$} & & [0.103] & {$[0.087]$} & & {$[0.098]$} & & [0.130] \\
\hline \multirow[t]{2}{*}{ JOE } & & $0.091^{*}$ & & 0.087 & 0.097 & & $0.133^{* *}$ & & $0.150^{* *}$ & 0.082 & & -0.046 & & -0.108 & 0.135 \\
\hline & & [0.049] & & [0.057] & [0.077] & & [0.060] & & {$[0.070]$} & [0.094] & & [0.077] & & {$[0.086]$} & [0.116] \\
\hline \multirow{2}{*}{$\triangle$ in UE (Start) } & & & 0.014 & & & & & 0.02 & & & & & 0.005 & & \\
\hline & & & [0.082] & & & & & [0.099] & & & & & [0.125] & & \\
\hline$\triangle$ in JOE & & & & $\begin{array}{c}0.008 \\
{[0.069]}\end{array}$ & & & & & $\begin{array}{c}-0.041 \\
{[0.085]}\end{array}$ & & & & & $\begin{array}{c}0.147 \\
{[0.099]}\end{array}$ & \\
\hline \multirow[t]{2}{*}{ Тор 30} & $1.592^{* * *}$ & $1.594 * * *$ & $1.593^{* * *}$ & $1.595^{* * *}$ & $1.594^{* * *}$ & $1.715^{* * *}$ & $1.717^{* * *}$ & $1.716^{* * *}$ & $1.715^{* * *}$ & $1.717^{* * *}$ & $1.178^{* * *}$ & $1.191^{* * *}$ & $1.178^{* * *}$ & $1.193^{* * *}$ & $1.175^{* * *}$ \\
\hline & [0.162] & {$[0.162]$} & {$[0.162]$} & [0.162] & [0.162] & [0.199] & [0.199] & [0.199] & [0.199] & [0.199] & {$[0.241]$} & [0.241] & {$[0.241]$} & {$[0.240]$} & {$[0.241]$} \\
\hline Female & $\begin{array}{c}-1.697 * * * \\
{[0.157]} \\
\end{array}$ & $\begin{array}{c}-1.692 * * * \\
{[0.157]}\end{array}$ & $\begin{array}{c}-1.697 * * * \\
{[0.157]}\end{array}$ & $\begin{array}{c}-1.692 * * * \\
{[0.157]}\end{array}$ & $\begin{array}{c}-1.692 * * * \\
{[0.157]}\end{array}$ & & & & & & & & & & \\
\hline Observ. & 4611 & 4611 & 4611 & 4611 & 4611 & 3673 & 3673 & 3673 & 3673 & 3673 & 938 & 938 & 938 & 938 & 938 \\
\hline Wald Stat. & 207,7 & 210 & 208 & 210.1 & 210.1 & 70.89 & 71.53 & 71.11 & 71.5 & 71.83 & 25.62 & 23.04 & 25.63 & 26.27 & 28.36 \\
\hline Log Likelihood & -12809 & -12808 & -12809 & -12808 & -12808 & -10457 & -10456 & -10456 & -10456 & -10456 & -2335 & -2336 & -2335 & -2335 & -2334 \\
\hline
\end{tabular}

Robust standard errors are reported in parentheses. ${ }^{* * *} p<0.1{ }^{* *} p<0.05{ }^{*} p<0.1$ 
Our findings for the pooled sample diverge from Boehm and Watzinger (2015) where unemployment rates at the start of graduate studies are shown to have positive and significant effect on research productivity. The correlation between number of publications and unemployment rate being statistically insignificant is most likely driven by individual level variation in our dependent variable. Boehm and Watzinger (2015) aggregate graduates' productivity at department-year level. Such aggregation is a valid practice, if explanatory variables do not vary at individual level but only at department-year level, as it is in their case. We avoid such aggregation by controlling for gender and thus introducing individual level variation in our explanatory variables. Avoiding such aggregations is potentially important, since research productivity follows an extremely skewed distribution: about $20 \%$ of most productive $\mathrm{PhDs}$ produce about $80 \%$ of all research output as shown by Conley et al. (2013). Joint significance of unemployment prior to starting the graduate school and academic job openings at the end is rejected at 10\% significance level in column 5 .

Significant and positive marginal effect of dummy variable "top 30" throughout all specifications reveals that graduates of top thirty economics departments perform significantly better than those of non-top thirty departments, which is a well-documented fact discussed in great detail by Conley et al. (2013). Significant and negative marginal effect of dummy variable "female" for the pooled sample reveals that female economics PhDs publish significantly less than their male counterparts.

Table 4. Number of Publications at Six Years after Graduation

$\begin{array}{rcccccccccc} & 1987 & 1988 & \mathbf{1 9 8 9} & \mathbf{1 9 9 0} & \mathbf{1 9 9 1} & \mathbf{1 9 9 2} & \mathbf{1 9 9 3} & \mathbf{1 9 9 4} & \mathbf{1 9 9 5} & \mathbf{1 9 9 6} \\ \text { Male PhDs } & 4.60 & 4.62 & 4.08 & 4.31 & 4.35 & 4.35 & 3.96 & 4.17 & 3.76 & 3.83 \\ \text { Female PhDs } & 3.05 & 3.63 & 2.80 & 2.82 & 3.26 & 2.90 & 2.96 & 3.36 & 3.33 & 3.33\end{array}$

The average number of publications (not adjusted for quality and not discounted for coauthorship) of male and female $\mathrm{PhDs}$ for each cohort at six years after their graduation is shown in table 4. Comparing numbers of publications of male and female PhDs at six years after graduation who succeed in publishing at least once within that time, we observe the following: publication count of an average female $\mathrm{PhD}$ in the 1987 cohort amounts to about $66 \%$ of that of a male $\mathrm{PhD}$ in the same cohort, whereas publications of an average female $\mathrm{PhD}$ in the 1996 cohort amount to about $87 \%$ of that of a male $\mathrm{PhD}$ in that cohort. Female PhDs publish less than male $\mathrm{PhDs}$, and the difference turns out to be statistically significant even after controlling for economic environment, job availability, and strength of the graduate institute. However it should not go unnoticed that the publication performance of female PhDs are catching up with that of male PhDs. 
Moving on from the results using pooled sample to using separate regressions for male and female $\mathrm{PhDs}$ it becomes obvious that results obtained in the pooled estimation have actually been blurred by pooling male and female PhDs together. An interesting finding about male graduates is that unemployment prior to start and job openings at the end are jointly significant, although both coefficients are individually insignificant ${ }^{7}$.

Specifications in the columns 7, 9, and 15 in panel A of table 3 show positive and statistically significant marginal effects for the number of academic job openings, meaning that academic job availability in the year when PhDs finish their studies is positively and significantly correlated with research productivity for male as well as for female PhDs. Availability of academic positions during the year of academic job search has a positive effect on research productivity of both male and female graduates. This finding is in line with Oyer (2006) who established a causal relationship between first job placement and research productivity, suggesting that a research-oriented first job increases research productivity by allowing fresh graduates to further develop their research skills. Such research positions are in abundant supply during years of good academic job market, and hence the probability of finding such a "skill-improving" first job is positively correlated with the volume of academic job advertisement.

Unemployment rates prior to starting graduate studies are positively correlated with male $\mathrm{PhDs}$ ' research productivity at six as well as nine years after graduation. These findings can be explained along the lines of simple human capital models focused on opportunity cost of human capital investment and self-selection of talent: during times of high unemployment, it is hard to find appealing and lucrative outside options, thus the opportunity cost of undertaking graduate studies decreases at such times. Economics graduate students are usually selected from a pool of highly qualified applicants in terms of their academic background (Grove and Wu, 2007). Given this background, it is presumed that these people face very high opportunity costs if they choose graduate school over work, as they forgo placement in well paying jobs with high skill requirements. In times of high unemployment, good jobs might disappear, thereby reducing the opportunity cost of joining a graduate program so that a greater number of individuals might be tempted to invest further in human capital.

\footnotetext{
${ }^{7}$ Since unemployment rate prior to $\mathrm{PhD}$ and number of job openings at the end of $\mathrm{PhD}$ may be expected to be correlated across time (due to fluctuations of the business cycle), this can lead to inflated standard errors which yield individual insignificance where it should not be. The variance inflation factor for both variables is about 2.4 , indicating non-orthogonality, but comfortingly low. Randomly dropping a year from our analysis creates no change in sign and no qualitative change in magnitude of regression coefficients.
} 
Following Roy's (Roy, 1951) argument for self-selection of talent into sectors where comparative advantage pays off most, it is straightforward to argue that incoming cohorts are comprised of more able students during years of high unemployment. We do not observe applications for graduate education, but since cohort sizes of economics PhDs are similar, it is fair to assume that incoming class sizes must be similar. Economics $\mathrm{PhD}$ education in the U.S. is mostly financed by departments through assistantships, and these are limited in supply no matter how big and talented the applicant pool may be. With a broader applicant pool and fairly stable class sizes, it is more likely that economics $\mathrm{PhD}$ cohorts in such years will be composed of more talented students.

Our results for female PhDs, however, tell a different story. Unemployment prior to starting graduate studies is negatively and significantly correlated with research output of female graduates at six years after graduation. Female PhDs in our sample accumulate on average 3.1 publications within six years after graduation. Coefficients in column 15 can be interpreted as follows: one percentage point increase in pre- graduate school unemployment rate decreases an average female PhD's research output by 0.21 publications. If the number of academic jobs advertised in JOE increase by 100 , this increases an average female graduate's research productivity by 0.12 publications. Although the effect of academic job openings is quantitatively small, it is statistically significant at $10 \%$ level.

This implies that the simple theory outlined for male graduates above does not apply to female graduates. A possible explanation for this finding might be that men and women react differently in risky situations, risk being in this context the choice of a research-active career. A research-active career is a risky path, because promotion strictly depends on publication success which has highly volatile outcomes. This could mean that rather more talented female candidates choose not to apply for graduate education during times of high unemployment, or alternatively more talented female graduates do not choose a research-active career after graduation and opt for more secure (and yet very well paying) jobs outside academia.

Both views are in line with the well-established experimental literature saying that in general women are more risk averse than men. ${ }^{8}$ Experimental work by Gneezy et al. (2003) claims that women are less effective than men in competitive environments, although no significant gender differences are observed in non-competitive environments. These experimental findings agree with survey results obtained by Ülkü-Steiner et al (2000) on 341 doctoral students where women in

\footnotetext{
${ }^{8}$ Borghans et al. (2009) provide a recent discussion and evidence on difference in risk aversion between men and women.
} 
male-dominated graduate programs expressed lower academic self-esteem and lower career commitment compared to male students.

Panel B in table 3 show how our results are affected when we consider a larger time span, namely nine years after graduation. Most of the qualitative results discussed above for the first six years after graduation continue to hold when the time span is extended to nine years. An average female $\mathrm{PhD}$ reaches 4.5 publications at nine years after graduation, and the unemployment rate prior to starting graduate studies still has a negative and significant effect on the stock of publications accumulated at nine years after graduation by female PhDs. A three percentage point increase in pre- graduate school unemployment rate costs an average female $\mathrm{PhD}$ about one publication. The number of academic job openings does not manifest itself as a statistically significant factor on size of publication stock reached by an average female $\mathrm{PhD}$ at nine years after graduation.

For male $\mathrm{PhDs}$ we find that unemployment rates prior to starting graduate school as well as the number of academic job openings are positively and significantly correlated with number of publications accumulated at nine years after graduation. Although both of these coefficients are individually insignificant in column 10 on panel B, they are jointly significant. An average male graduate achieves about 6.2 publications at nine years after graduation. Comparing this average to the level of estimated coefficients, one must acknowledge that statistical significance once again does not necessarily carry over to economic significance in case of male PhDs.

Table 5. Number of AER Equivalent Publications at Six Years after Graduation

$\begin{array}{rcccccccccc} & 1987 & 1988 & 1989 & 1990 & 1991 & 1992 & 1993 & 1994 & 1995 & 1996 \\ \text { Male PhDs } & 0.463 & 0.419 & 0.330 & 0.345 & 0.350 & 0.369 & 0.301 & 0.306 & 0.280 & 0.267 \\ \text { Female PhDs } & 0.300 & 0.369 & 0.192 & 0.159 & 0.256 & 0.215 & 0.217 & 0.260 & 0.277 & 0.232\end{array}$

The question remains whether the results continue to hold when research productivity is adjusted for the quality of the outlet and for number of coauthors. Table 5 shows the average number of AER equivalent publications (hence adjusted for quality and discounted for coauthorship) of male and female $\mathrm{PhDs}$ for each cohort at six years after their graduation. Number of AER equivalent publications of average male and female $\mathrm{PhDs}$ in the 1987 cohort is 0.46 and 0.3 AER papers, respectively. AER equivalent publications of an average female $\mathrm{PhD}$ in that cohort amounts to about $65 \%$ of that of a male $\mathrm{PhD}$ in the same cohort. Except for the 1990 cohort where female PhDs score less than half of what male PhDs score, and except for the 1995 cohort where female and male PhDs score almost the same, the ratio of female to male $\mathrm{PhD}$ productivity measured by 
the number of AER equivalent (quality-adjusted and coauthor-discounted) publications remains very similar to that observed in table 4 for the ratio of raw number of publications of female to male PhDs. We also checked for the number of coauthor-discounted publications (without quality adjustment) and found that discounting for coauthorship does not deflate female $\mathrm{PhDs}$ ' number of publications more drastically than it deflates male $\mathrm{PhDs}$ ' publications.

Table 6 shows OLS coefficients using coauthor-discounted AER equivalent number of publications achieved by the end of six and nine years after graduation as dependent variable in panels A and B, respectively. Standard errors are clustered at graduation year and top thirty departments.

Controlling for quality of research output, we still obtain qualitatively very similar results in Table 6 to those presented in Table 3. Thus our finding of negative selection of female students into graduate studies during high unemployment years has statistical as well as economic significance even after adjusting research output for coauthorship and publication quality. Unemployment rate prior to starting graduate studies is significantly and positively correlated with quality-adjusted research output of male graduates. An average male graduate produces about 0.34 AER equivalent publications at six years after graduation. One percentage point increase in the unemployment rate prior to starting $\mathrm{PhD}$ is significantly correlated with a $5 \%$ increase in that quality-adjusted productivity measure. Number of job openings at the end of graduate studies is also significantly and positively correlated with male graduates' quality-adjusted research output, and this significance does not disappear when we control for the change in number of job openings from the previous year.

An average female graduate publishes about 0.24 AER equivalent papers in six years after graduation, and one percentage point increase in unemployment rate prior to starting graduate school is related to a decrease of 0.0139 to 0.0253 AER equivalent papers, which amount to about 6 to $11 \%$ decrease in quality-adjusted research output of the average female graduate. Significance of this coefficient does not disappear when we also control for the change in unemployment rate or for the number of job openings at graduation. 
Table 6. Unemployment and Research Productivity (Total Number of AER Equivalent Publications)

\begin{tabular}{|c|c|c|c|c|c|c|c|c|c|c|}
\hline & \multicolumn{10}{|c|}{ A. 6 Years After Obtaining $\mathrm{PhD}$} \\
\hline & \multicolumn{5}{|c|}{ A. 0 Y Teals Alle } & \multicolumn{5}{|c|}{ Female } \\
\hline & (1) & (2) & (3) & (4) & (5) & (6) & (7) & (8) & (9) & (10) \\
\hline \multirow[t]{2}{*}{ UE (Start) } & $0.0164 * *$ & 0.0123 & & & 0.0135 & $-0.0139^{*}$ & $-0.0162^{*}$ & & & $-0.0253^{* *}$ \\
\hline & {$[0.007]$} & [0.010] & & & [0.012] & {$[0.007]$} & [0.009] & & & [0.009] \\
\hline \multirow[t]{2}{*}{ JOE } & & & $0.0129 *$ & $0.0153 *$ & 0.0035 & & & -0.0037 & -0.0106 & $0.0136^{*}$ \\
\hline & & & [0.007] & {$[0.008]$} & [0.012] & & & {$[0.008]$} & [0.008] & {$[0.007]$} \\
\hline \multirow[t]{2}{*}{$\triangle$ in UE (Start) } & & 0.0117 & & & & & 0.006 & & & \\
\hline & & [0.020] & & & & & {$[0.011]$} & & & \\
\hline$\triangle$ in JOE & & & & $\begin{array}{c}-0,006 \\
{[0.008]}\end{array}$ & & & & & $\begin{array}{c}0.0164 * * \\
{[0.007]}\end{array}$ & \\
\hline \multirow[t]{2}{*}{ Тор 30} & $0.3112^{* * *}$ & $0.3116^{* * *}$ & $0.3113^{* * *}$ & $0.3111^{* * *}$ & $0.3113^{* * *}$ & $0.1587^{* * *}$ & $0.1586^{* * *}$ & $0.1600^{* * *}$ & $0.1594 * * *$ & $0.1581^{* * *}$ \\
\hline & [0.025] & {$[0.026]$} & [0.025] & {$[0.025]$} & [0.025] & {$[0.021]$} & {$[0.021]$} & [0.023] & [0.021] & {$[0.020]$} \\
\hline \multirow[t]{2}{*}{ Constant } & 0.0229 & 0.0539 & -0.0133 & -0.0426 & 0.0021 & $0.2450^{* * *}$ & $0.2622 * * *$ & $0.1884 * *$ & $0.2735^{* * *}$ & $0.1652^{* *}$ \\
\hline & [0.045] & {$[0.068]$} & {$[0.082]$} & {$[0.090]$} & [0.084] & [0.055] & {$[0.070]$} & {$[0.090]$} & [0.091] & {$[0.070]$} \\
\hline Observ. & 3673 & 3673 & 3673 & 3673 & 3673 & 938 & 938 & 938 & 938 & 938 \\
\hline Adj. $R$-squared & 0.052 & 0.052 & 0.052 & 0.051 & 0.052 & 0.028 & 0.027 & 0.026 & 0.027 & 0.028 \\
\hline F Stat. & 95.96 & 148 & 108.5 & 73.7 & 83.54 & 32.83 & 25.61 & 27.8 & 20.46 & 24.16 \\
\hline
\end{tabular}


Table 6. Unemployment and Research Productivity (Total Number of AER Equivalent Publications) (cont.'ed)

\begin{tabular}{|c|c|c|c|c|c|c|c|c|c|c|}
\hline & \multicolumn{10}{|c|}{ B. 9 Years After Obtaining PhD } \\
\hline & \multicolumn{5}{|c|}{ Male } & \multicolumn{5}{|c|}{ Female } \\
\hline & (1) & (2) & (3) & (4) & (5) & (6) & (7) & (8) & (9) & (10) \\
\hline UE (Start) & $0.0183 * *$ & 0.0118 & & & 0.0159 & $-0.0259 * *$ & $-0.0314 * *$ & & & $-0.0307^{*}$ \\
\hline & [0.009] & [0.013] & & & {$[0.017]$} & {$[0.012]$} & {$[0.014]$} & & & {$[0.015]$} \\
\hline JOE & & & 0.014 & $0.0185^{*}$ & 0.0029 & & & -0.0153 & $-0.0248 * *$ & 0.0058 \\
\hline & & & [0.010] & {$[0.011]$} & [0.019] & & & [0.011] & [0.011] & [0.011] \\
\hline$\triangle$ in UE (Start) & & 0.0183 & & & & & 0.0145 & & & \\
\hline & & {$[0.026]$} & & & & & [0.011] & & & \\
\hline$\triangle$ in $J O E$ & & & & $\begin{array}{l}-0.0113 \\
{[0.013]}\end{array}$ & & & & & $\begin{array}{c}0.0226^{* *} \\
{[0.010]}\end{array}$ & \\
\hline Top 30 & $\begin{array}{c}0.4596 * * * \\
{[0.036]}\end{array}$ & $\begin{array}{c}0.4602 * * * \\
{[0.037]}\end{array}$ & $\begin{array}{c}0.4597 * * * \\
{[0.036]}\end{array}$ & $\begin{array}{c}0.4593 * * * \\
{[0.035]}\end{array}$ & $\begin{array}{c}0.4597 * * * \\
{[0.035]}\end{array}$ & $\begin{array}{c}0.2409 * * * \\
{[0.029]}\end{array}$ & $\begin{array}{c}0.2407 * * * \\
{[0.028]}\end{array}$ & $\begin{array}{c}0.2430 * * * \\
{[0.031]}\end{array}$ & $\begin{array}{c}0.2422 * * * \\
{[0.029]}\end{array}$ & $\begin{array}{c}0.2406^{* * *} \\
{[0.028]}\end{array}$ \\
\hline Constant & $\begin{array}{c}0.0581 \\
{[0.059]}\end{array}$ & $\begin{array}{l}0.1066 \\
{[0.087]}\end{array}$ & $\begin{array}{l}0.0227 \\
{[0.119]}\end{array}$ & $\begin{array}{l}-0.0327 \\
{[0.128]}\end{array}$ & $\begin{array}{l}0.0408 \\
{[0.127]}\end{array}$ & $\begin{array}{c}0.3686^{* * *} \\
{[0.088]}\end{array}$ & $\begin{array}{c}0.4102 * * * \\
{[0.105]}\end{array}$ & $\begin{array}{c}0.3630^{* *} \\
{[0.128]}\end{array}$ & $\begin{array}{c}0.4805^{* * *} \\
{[0.136]} \\
\end{array}$ & $\begin{array}{c}0.3349 * * * \\
{[0.111]}\end{array}$ \\
\hline Observ. & 3673 & 3673 & 3673 & 3673 & 3673 & 938 & 938 & 938 & 938 & 938 \\
\hline Adj. R-squared & 0.057 & 0.057 & 0.056 & 0.056 & 0.056 & 0.036 & 0.036 & 0.034 & 0.035 & 0.035 \\
\hline F Stat. & 92.59 & 114.3 & 99.7 & 71.67 & 74.25 & 36.37 & 24.4 & 32.61 & 24.07 & 24.8 \\
\hline
\end{tabular}

Clustered standard errors are reported in parentheses. ${ }^{* * *} p<0.1 * * p<0.05 * p<0.1$ 
Regression results for coauthor and quality-adjusted number of publications achieved nine years after graduation in panel B reveal a very similar story as that at six years after graduation. We obtain qualitatively almost same results at nine years as at six years after graduation for male PhDs. Academic job availability has a negative and significant, and the change in it has positive and significant point estimate in case of female PhDs, but these turn out insignificant when estimated with unemployment rate variable in the same specification. Pre- graduate school unemployment rates consistently have negative and significant point estimates in all specifications for female graduates.

\subsection{Selection}

So far we focused on publishing graduates only, and have shown that unemployment prior to the start of graduate studies and availability of academic jobs at the time of junior job market have different effects on research productivities of male and female PhDs. Considering the fact that about $50 \%$ of PhDs in any cohort never ever publish (Conley et al. 2013, Conley and Önder 2014), the next question is whether these patterns are preserved when we investigate PhDs' probability of becoming a "publishing PhD", meaning that they publish at least once within six years after graduation. We estimate a probit model with a binary dependent variable and the same independent variables as in tables 3 and 6 . The dependent variable is one, if a $\mathrm{PhD}$ published at least once in a peer-reviewed journal cited in the EconLit database within six years after graduation, and zero otherwise. Our findings are robust to defining "publishing PhDs" as those who publish at least twice within six years after graduation.

Unemployment prior to starting graduate studies has a negative and statistically significant effect on the probability of publishing at least once for male graduates: an increase of one percentage point in unemployment is associated with a 0.7 to 1 percentage point decrease in the probability of ever publishing. This works in the opposite way for female graduates: one percentage point increase in unemployment is associated with 2.2 percentage point increase in probability of publishing. Furthermore, for female graduates, an increase of 100 academic openings is associated with 1.5 percentage point increase in the probability of publishing. Although statistically significant, one should note that, given variations in unemployment rates and academic job advertisements, these probabilities are hardly economically significant. Especially in case of male graduates, no economic significance can be claimed, which can be a result of low variation in share of publishing male graduates across cohorts as documented in table 2 . 
Table 7. Probability of Publishing after PhD

\begin{tabular}{|c|c|c|c|c|c|c|c|c|c|c|c|c|c|c|c|}
\hline \multirow{4}{*}{ UE (Start) } & \multicolumn{5}{|c|}{ All } & \multicolumn{5}{|c|}{ Male } & \multicolumn{5}{|c|}{ Female } \\
\hline & (1) & (2) & (3) & (4) & (5) & (6) & (7) & (8) & (9) & (10) & (11) & (12) & (13) & (14) & (15) \\
\hline & -0.003 & -0.002 & & & -0.003 & $-0.007 * *$ & -0.004 & & & $-0.010 * *$ & 0.01 & 0.008 & & & $0.022^{* *}$ \\
\hline & {$[0.004]$} & {$[0.004]$} & & & {$[0.005]$} & {$[0.003]$} & {$[0.003]$} & & & {$[0.005]$} & [0.008] & {$[0.008]$} & & & {$[0.011]$} \\
\hline \multirow[t]{2}{*}{ JOE } & & & -0.002 & -0.002 & -0.001 & & & -0.003 & -0.004 & 0.003 & & & 0.001 & 0.003 & $-0.015^{*}$ \\
\hline & & & {$[0.003]$} & [0.003] & {$[0.004]$} & & & {$[0.003]$} & {$[0.004]$} & {$[0.003]$} & & & [0.007] & [0.008] & [0.009] \\
\hline \multirow[t]{2}{*}{$\triangle$ in UE (Start) } & & -0.004 & & & & & -0.007 & & & & & 0.005 & & & \\
\hline & & [0.005] & & & & & [0.004] & & & & & [0.012] & & & \\
\hline \multirow[t]{2}{*}{$\triangle$ in JOE } & & & & -0.0002 & & & & & 0.001 & & & & & -0.006 & \\
\hline & & & & [0.004] & & & & & {$[0.004]$} & & & & & [0.009] & \\
\hline \multirow[t]{2}{*}{ Top 30} & $0.205^{* * *}$ & $0.205^{* * *}$ & $0.205^{* * *}$ & $0.205^{* * *}$ & $0.205^{* * *}$ & $0.209^{* * *}$ & $0.209 * * *$ & $0.209^{* * *}$ & $0.209^{* * *}$ & $0.209^{* * *}$ & $0.192 * * *$ & $0.192^{* * *}$ & $0.191 * * *$ & $0.191 * * *$ & $0.192 * * *$ \\
\hline & {$[0.011]$} & {$[0.010]$} & [0.011] & {$[0.011]$} & [0.011] & {$[0.009]$} & [0.009] & {$[0.010]$} & {$[0.010]$} & {$[0.009]$} & {$[0.025]$} & [0.024] & {$[0.026]$} & {$[0.026]$} & {$[0.024]$} \\
\hline Female & $\begin{array}{c}-0.038 * * * \\
{[0.013]} \\
\end{array}$ & $\begin{array}{c}-0.038^{* * *} \\
{[0.013]}\end{array}$ & $\begin{array}{c}-0.038^{* * *} \\
{[0.013]} \\
\end{array}$ & $\begin{array}{c}-0.038 * * * \\
{[0.013]}\end{array}$ & $\begin{array}{c}-0.038 * * * \\
{[0.013]} \\
\end{array}$ & & & & & & & & & & \\
\hline Observ. & 9368 & 9368 & 9368 & 9368 & 9368 & 7339 & 7339 & 7339 & 7339 & 7339 & 2029 & 2029 & 2029 & 2029 & 2029 \\
\hline Wald Stat. & 384.1 & 461.7 & 371.1 & 371.3 & 384.2 & 481.4 & 545.8 & 463.8 & 470.2 & 507.9 & 56.94 & 90.34 & 55.64 & 60.65 & 71.61 \\
\hline Log Likelihood & -6289 & -6288 & -6289 & -6289 & -6289 & -4925 & -4924 & -4926 & -4925 & -4924 & -1362 & -1362 & -1363 & -1363 & -1361 \\
\hline
\end{tabular}


There are two interesting findings one can draw from the probit results in table 7: first, statistically significant coefficient estimates for unemployment prior to starting graduate studies and academic job openings in columns 10 and 15 have exactly opposite signs as their counterparts in tables 3 and 6 . With these findings at hand, we cannot reject the following alternative line of thinking: talented female students enter graduate education during times of high unemployment, and they are motivated students, probably publishing some of their dissertation chapters, so that they appear as "publishing PhDs" in our data. However they either do not take a research-active career upon graduation or if they do they switch within a few years. This would explain the observed increased likelihood of publishing at least once, because these female student cohorts are obviously talented and motivated. Upon graduation or shortly thereafter, they switch to occupations where they are not required to publish research, so that our results about female PhDs' research productivity presented in tables 3 and 6 are driven by talented female graduates who published some articles early on and then withdrew from research intensive occupations. This creates high volatility in the total number of female PhDs' publications across cohorts, which is documented by the high variation in ratio of publishing female graduates in tables 2, 4, and 5. Moreover this explains why the sign for the unemployment rate prior to starting $\mathrm{PhD}$ education switches from negative in tables 3 and 6 to positive in table 7 .

This line of thinking supports the view that with respect to women, there is not necessarily a negative selection of talent when opportunity cost of human capital investment decreases. That is, talented women select themselves into graduate education during recession as their male counterparts do. However, upon graduation they opt for a less risky occupation than a researchactive career. Thus, risk-aversion may be the key element in allocation of female talent across high skill occupations. This can be a potential explanation for observed differences in gender unemployment rates across different occupation categories that were documented by Rives and Sosin (2002).

From the viewpoint of economic significance, one can argue that the unemployment rate prior to start of graduate education and the number of academic jobs at time of graduation have an impact on the intensive margin but not on the extensive margin of research productivity among $\mathrm{PhDs}$. Extensive margin in this context is the decision about becoming a "publishing PhD" or not, and intensive margin, on the other hand, is quantity and quality of research output. 


\section{Conclusion}

Using a unique dataset on graduates of economics doctorate programs in the U.S. from 1987 to 1996 we investigate if and how economic conditions prevailing in the economy prior to start and the availability of academic job openings at time of graduation are correlated with observed research productivities (measured in raw as well as quality-adjusted numbers of publications) of male and female economics PhDs. We find that favorable conditions at the time of academic job search are positively correlated with research productivity for both male and female PhDs. High unemployment rates at the time of entry into graduate school correlate negatively with female PhDs' research productivity and positively with male PhDs' productivity. This is an interesting result, because it points to an important difference between men and women concerning the dynamics of decision making process to attend graduate school and to take research-active careers.

A possible explanation for this finding might be that men and women react differently in risky situations. This could mean that rather more talented female candidates choose not to apply for graduate education during times of high unemployment, or alternatively more talented female graduates do not choose a research-active career after graduate education and opt for possibly more secure (and yet very well paying) jobs outside academia. Nevertheless, according to our results on "selection into publishing", talented female students actually select themselves into graduate education during recession as their male counterparts do. However, upon graduation they apparently do not opt for a research-active career. Based on these observations, we suspect that the difference in risk-aversion of men and women may be one of the key elements driving the observed underrepresentation of women in research-active careers, such as faculty positions.

This paper contributes to the current literature by documenting research output of male and female economics $\mathrm{PhDs}$ and further bridging the literature on selection of talent into occupations and the extensive literature on gender gap in the academia. It would be interesting to see how robust these findings are to variations in the duration of business cycles. We leave this for further research. 


\section{References}

Barbezat, D.A. 2006. Gender differences in research patterns among $\mathrm{PhD}$ economists. Journal of Economic Education. 37(3): 359-375.

Bedard, K., Herman, D.A. 2008. Who goes to graduate/professional school? The importance of economic fluctuations, undergraduate field, and ability. Economics of Education Review. 27: 197210.

Boehm, M.J., Watzinger, M. 2015. The allocation of talent over the business cycle and its longterm effect on sectoral productivity. Economica. 82(328): 892-911.

Borghans, L, Golsteyn, B. H. H., Heckman, J. J., Meijers, H. 2009. Gender differences in risk aversion and ambiguity aversion. Journal of the European Economic Association. 7: 649-658.

Ceci, S.J., Ginther, D.K., Kahn, S., Williams, W.M. 2014. Women in academic science: a changing landscape. Psychological Science in the Public Interest. 15(3): 75-141.

Conley, J.P., Crucini, M.J., Driskill, R.A., Önder, A.S. 2013. Incentives and effects of publication lags on life cycle research productivity in economics. Economic Inquiry. 51(2): 1251-1276.

Conley, J.P., Önder, A.S. 2014. The research productivity of new PhDs in economics: the surprisingly high non-success of the successful. Journal of Economic Perspectives. 28(3): 205216.

Coupé, T. 2003. Revealed performances: worldwide rankings of economists and economics departments 1990-2000. Journal of the European Economic Association. 1: 1309-1345.

Ellison, G. 2002. The slowdown of the economics publishing process. Journal of Political Economy. 110(5): 947-993.

Ginther, D.K., Kahn, S. 2004. Women in economics: moving up or falling off the academic career ladder. Journal of Economic Perspectives. 18(3): 193-214.

Gneezy, U., Niederle, M., Rustichini, A. 2003. Performance in competitive environments: gender differences. Quarterly Journal of Economics. 118: 1049-1074.

Grove, W.A., Wu, S. 2007. The search for talent: doctoral completion and research productivity. American Economic Review. 97: 506-511.

Hale, G., Regev, T. 2014. Gender ratios at top PhD programs in economics. Economics of Education Review. 41: 55-70.

Hilmer, C., Hilmer, M. 2007. Women helping women? Same gender mentoring, initial job placements, and early career publishing success for economics PhDs. American Economic Review. 97(2): 422-426.

Kalaitzidakis, P., Mamuneas, T.P., Stengos, T. 2003. Rankings of academic journals and institutions in economics. Journal of the European Economic Association. 1: 1346-1366. 
Oreopoulos, P., v.Wachter, T., Heisz, A. 2012. The short- and long-term career effects of graduating in a recession. American Economic Journal: Applied Economics. 4(1): 1-29.

Oyer, P. 2006. Initial Labor Market Conditions and Long-Term Outcomes for Economists. Journal of Economic Perspectives, 20(3): 143-160.

Rives, J.M., Sosin, K. 2002. Occupations and the cyclical behavior of gender unemployment rates. Journal of Socio-Economics. 31: 287-299.

Roy, A.D. 1951. Some thoughts on distribution of earnings. Oxford Economic Papers. 3: 135-146.

Stock, W.A., Finegan, T.A., Siegfried, J.A. 2009. Completing an economics PhD in five years: let the data (literally) speak for themselves. American Economic Review. 99: 624-629.

Ülkü-Steiner, B., Kurtz-Costes, B., Kinlaw, C.R. 2000. Doctoral student experiences in genderbalanced and male-dominated graduate programs. Journal of Educational Psychology. 92(2): 296-307. 